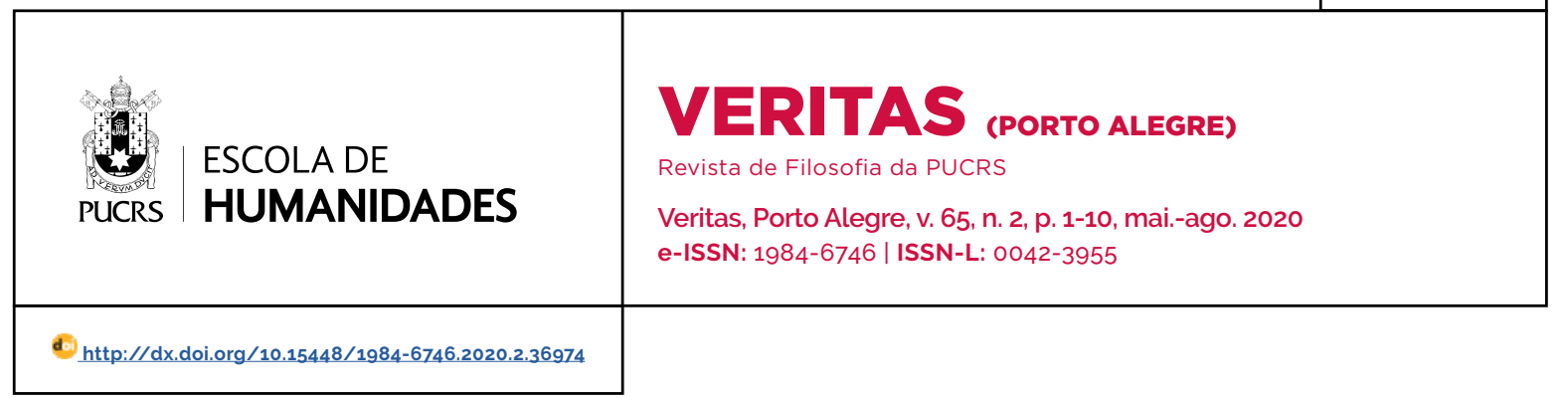

SEÇÃO: AESTHETICS

\title{
Música e linguagem na forma-ensaio. Sobre alguns motivos em T. W. Adorno
}

\author{
Music and language in the essay-form. On some motifs in T. W. Adorno \\ Música y lenguaje em la forma-ensayo. Acerca de algunos motivos en T. W. Adorno
}

\section{Ricardo Barbosa ${ }^{1}$ \\ orcid.org/0000-0003-4179-9093 \\ ricjcb@gmail.com}

Recebido em: 29 jan. 2020 Aprovado em: 13 mar. 2020. Publicado em: 28 jul. 2020.

\section{(c) (i)}

Artigo está licenciado sob forma de uma licença Creative Commons Atribuição 4.0 Internacional.
Resumo: O artigo procura mostrar como alguns dos principais motivos da filosofia de Adorno, tais como a critica ao sistema e ao pensamento discursivo, a superação do conceito pelo próprio conceito, o resgate do não-idêntico e a configuração do nome, constituem a "constelação de música e palavra", característica da já clássica apologia adorniana da forma-ensaio, da qual também resultam suas debilidades.

Palavras-chave: Adorno. Ensaio. Música. Estética. Teoria crítica.

Abstract: The article aims to show how some of the main motifs of Adorno's philosophy, such as the critique of the system and the discursive thought, the overcoming of the concept through the concept itself, the rescue of the non-identical and the configuration of the name, constitute the "constellation of music and word", characteristic of the already classic adornian apology of the essay-form, from which result also its weaknesses.

Keywords: Adorno. Essay. Music. Aesthetic. Critical Theory.

Resumen: El artículo procura mostrar como algunos de los principales motivos de la filosofía de Adorno, como por ejemplo la critica al sistema y al pensamiento discursivo, la superación del concepto por el proprio concepto, el rescate de lo no-idéntico y la configuración del nombre, constituyen la "constelación de música y palabra", caracteristica de la clássica apología adorniana de la forma-ensayo, de la que también resultan sus debilidades.

Palavras clave: Adorno. Ensayo. Música. Estética. Teoria crítica.

Como o jovem Lukács, Adorno também deixou uma apologia do ensaio inteiramente pro domo sua. Escrita entre 1954-1958 e sem uma única referência à ainda incipiente literatura acadêmica sobre o tema, ${ }^{2}$ Adorno a intitulou "O ensaio como forma" - como forma. Torna-se claro desde o início que está em jogo uma questão de direito: o que legitima a pretensão de autonomia por vezes reivindicada para esse "produto híbrido" (ADORNO, 1986a, p. 167) e um tanto suspeito? Talvez por isso Adorno não tenha se voltado explicitamente para uma tradição já centenária, bem ou mal consolidada por Hermann Grimm com os seus Essays (1859), mas cuja hora natal remontaria à Aufklärung, estendendo-se de Lessing a Dilthey (KAYSER, 1925, p. 1313-1318), embora não se possa pensar em outra coisa quando, aludindo a figuras como Georg Simmel e Walter Benjamin, menciona o preconceito da "corporação acadêmica" contra

\footnotetext{
1 Universidade do Estado do Rio de Janeiro (Uerj), Rio de Janeiro, RJ, Brasil.

Hoje imensa, a literatura acadêmica sobre o ensaio só passaria a um novo patamar com o trabalho ainda incontornável de Ludwig Rohner, Der deutsche Essay. Materialien zur Geschichte und Ästhetik einer literarischen Gattung. Neuwied e Berlim: Luchterhand, 1966.
} 
o ensaísmo e as debilidades de uma cultura autoritária como a alemã, da qual o "homme de lettres" ainda destoaria como uma frágil exceção (ADORNO, 1986a, p. 167-168). Compreende-se assim porque Adorno se volta diretamente para Lukács, um rebento tardio e egresso de um milieu relativamente periférico - o da Budapeste dos últimos anos do Império Austro-húngaro. Afinal, o jovem crítico, chamado à filosofia por amor à literatura, fora o primeiro a formular explicitamente aquele problema e a declarar que o ensaio ainda não havia conquistado sua emancipação como uma forma autônoma, mas que chegara a sua hora.

No escrito de abertura de A alma e as formas (1911), "Sobre a essência e a forma do ensaio: uma carta a Leo Popper", Lukács defendeu a crítica como arte e o ensaio como uma forma artística (LUKÁCS, 1971, p. 7-31). Assim, ele se reconheceu em uma tradição que, nascida no romantismo de Jena, com Novalis e Friedrich Schlegel, teria chegado ao presente através de figuras tão diversas quanto o Oscar Wilde de $O$ crítico como artista, o "platônico" Rudolf Kassner e um rival de Karl Kraus, o influente crítico teatral berlinense Alfred Kerr, com quem Lukács poderia ter dito: "A poesia (Dichtung) decompõe-se em épica, lírica, dramática e crítica" (KERR, 1972, p. 4). O ensaio seria, então, algo como o quarto gênero poético. Adorno repetiu o gesto do Lukács de A alma e as formas e abriu um livro de ensaios sobre literatura justamente com um ensaio sobre o ensaio; no entanto, diferentemente de Lukács, ele reivindicou para a forma ensaio o direito a uma outra identidade, em parte estética, mas não mais artística, além de igualmente distante da convicção oposta: "a máxima positivista de que o escrito sobre arte não deveria ter, em si, nada de artístico, e portanto não deveria pretender qualquer autonomia da forma" (ADORNO, 1986a, p. 169). Essa apologia do ensaio é, de resto, uma espécie de continuação do finale da preleção inaugural de seu autor na Universidade de Frankfurt, "A atualidade da filosofia" (1931), quando,

antecipando-se a possiveis objeções, saira em defesa da dignidade do ensaísmo na filosofia (ADORNO, 1997a, p. 343-343).

O volume de ensaios sobre literatura, publicado em 1958, foi o primeiro de uma série de três, todos com o mesmo título. De início Adorno escolhera Palavras sem canções, em uma alusão a Mendelssohn (Lieder ohne Worte) e talvez a Verlaine (Romances sans paroles). ${ }^{3}$ Ele já dera esse título a uma série de aforismos estampada em 1931 no Frankfurter Zeitung, mas, mesmo assim, queria retomá-lo. No entanto, Peter Suhrkamp, seu amigo e editor, o achava "por demais folhetinesco e ordinário" (ADORNO, 1997b, p. 328). Entre as várias alternativas que sugeriu, Adorno aceitou a última: Notas de literatura.

Isso era incomparavelmente bem melhor que
o meu bonmot algo tolo. Mas o que me en-
cantou foi que, enquanto criticou minha ideia,
Suhrkamp a manteve. A constelação de música
e palavra é salva do mesmo modo que o ca-
ráter levemente fora de moda de uma forma
cujo periodo de esplendor fora o Jugendstil
(ADORNO, 1997b, p. 328-329).

Essa "constelação de música e palavra" é característica do que o ensaísmo tornou-se nas mãos de Adorno: o ensaio como forma significa antes o ensaio como forma da "teoria crítica", embora em sua apologia não fale por "escola" alguma. Se em algum momento ela se estende a algum outro autor, então é a Walter Benjamin, sobre cujo ensaísmo Adorno escreveu com intimidade e reconhecimento. Um dos motivos - talvez o principal - visado pelo meu subtítulo é originariamente um motivo benjaminiano: a configuração do "nome"; mas comecemos pelo que é destacado no título. A referência direta à música e o uso da expressão "forma-ensaio" sugerem relações com as formas musicais. De fato, gostaria de partir do conceito de forma na música. Arnold Schönberg o definiu sob dois aspectos. O primeiro é o mais técnico e usual: diz respeito ao número de partes, à extensão e às relações entre essas partes em uma peça musical. Fala-se assim na forma sonata, na forma

\footnotetext{
3 A referência a Verlaine foi assinalada por Ulrich Plass, Language and History in Theodor W. Adorno's Notes to Literature. N. York e Londres: Routledge, 2012, p. 185.
} 
rondó etc. Sob esse aspecto, o ensaio seria, na melhor das hipóteses, comparável apenas à rapsódia, uma forma musical quase inteiramente sem regras no tocante à economia das partes e ao caráter, e por isso tão livre quanto o capriccio, o impromptu e a fantasia. O título de uma das melhores reuniões de ensaios musicais de Adorno, Quasi una fantasia, não se deixa ler apenas como uma alusão direta às duas sonatas para piano que formam o opus 27 de Beethoven; indiretamente, adverte acerca da autonomia do ensaio, ou seja, da liberdade formal que the é conferida pelo seu impulso antissistemático e com a qual se aproxima mimeticamente dos seus objetos. "É inerente à forma do ensaio a sua própria relativização: ele precisa compor-se de tal modo como se, a todo momento, pudesse interromper-se. Ele pensa aos solavancos e aos pedaços, assim como a realidade é descontínua; encontra a sua unidade através de rupturas e não à medida que as escamoteia" (ADORNO, 1986a, p. 180). É significativo que Adorno tenha se referido à objeção sistemática de Kant contra o pensamento "rapsódico" de Aristóteles justamente enquanto impugnava inteiramente o princípio e o projeto cartesiano, contra o qual mobiliza o ensaio: "Em seu conjunto, ele deveria ser interpretado como um protesto contra as quatro regras que - Discours de la méthode de Descartes erige no início da moderna ciência ocidental e de sua teoria" (ADORNO, 1986a, p. 179, 177). Isso já nos leva ao segundo aspecto do conceito de forma.

Esse aspecto - o estético - remonta evidentemente à filosofia clássica alemã. "Em um sentido estético, o termo forma significa que a peça é 'organizada', isto é, que ela está constituida de elementos que funcionam tal como um organismo vivo" (SCHÖNBERG, 2012. p. 28). O organismo foi tomado como modelo tanto pela ciência quanto pela arte; e quando digo pela ciência, penso antes na antagonista do ensaio, na filosofia entendida como a ciência universal e em sua estrutura como um sistema. O orgânico na filosofia seria justamente a forma sistemática. Na filosofia como na arte, o orgânico é inteiramente oposto ao mecânico, pois enquanto esse é expansivel pela agregação exterior de novas partes, aquele, como algo vivo, cresce de dentro para fora. Um agregado pode ser aumentado, mas um sistema é algo passivel de desenvolvimento a partir de um núcleo inicial. Em filosofias como a de Descartes e a de Fichte, tudo deve poder ser derivado de uma proposição seminal, de um primeiro princípio absolutamente certo, assim como na tradição musical peças inteiras são "derivadas" de um simples motivo inicial, uma célula formadora de todos os tecidos e do completo organismo. Seja na música, seja na filosofia, tudo deve poder ser gerado ab ovo.

É antes de tudo contra isso que o ensaio se volta. "Em relação ao procedimento científico e à sua fundamentação filosófica como método", escreveu Adorno, "o ensaio, de acordo com sua própria ideia, tira todas as consequências da crítica ao sistema" (ADORNO, 1986a, p. 173). Mas a crítica ao sistema não implica a renúncia à forma orgânica e ao pensamento motívico. Ao contrário de Descartes e Fichte, que teceram as teias dos seus sistemas com o fio gerado da suposta pureza do espírito, o ensaísta conta apenas com a experiência sedimentada nos seus objetos e na própria linguagem. Seus achados são, sobretudo, achados sobre o que ele encontra; e se se tornam em seus motivos, ele frequentemente os desenvolve mediante variações progressivas, quando cesuras bruscas e contrastantes podem se alternar com transições discretas e sutis. Assim ele também lida com os seus próprios limites formais, ou seja, com o nexo entre as suas partes e o todo e com a coisa mesma de que trata, de modo a estar sempre $\dot{a}$ point, sempre in media res.

Ele não começa com Adão e Eva, mas com aquilo de que quer falar; diz o que lhe ocorre, termina onde ele mesmo acha que acabou e não onde nada mais resta a dizer: assim ele se insere entre os despropósitos. Seus conceitos não se constroem a partir de algo primeiro nem se fecham em algo último (ADORNO, 1986a, p. 168).

Assim o ensaio também se aproxima da reação da música nova contra os rígidos topoi da tradicional. "O momento orgânico, central para o classicismo vienense, esse momento daquilo que 
se desenvolve, demonstra ser, frente a esses topoi, em grande parte, uma arte da aparência", como mostrara Rudolf Kolisch em um revelador trabalho sobre Beethoven, mencionado aqui por Adorno:

a música se apresenta como se uma coisa se desenvolvesse a partir da outra, sem que literalmente ocorra tal desenvolvimento. 0 aspecto mecânico acaba sendo superado pela arte da composição, mas é incomparavelmente mais forte do que possa ser agradável à fé na cultura. Ele é profundamente aparentado tanto ao espirito das ciências naturais quanto ao espirito burguês. De modo muito semelhante, também os grandes sistemas filosóficos a partir de Platão, reiteradamente lançaram mão, com alguma ingenuidade, desses meios mecânicos, contra os quais deveria ter-se revoltado o pathos do espírito, que neles prevalece. O mal- estar perante tal montagem caleidoscópica e mecânica a partir de elementos levou a uma música que queria ser livre disso (ADORNO, 1986b, p. 153-154).

Reagindo ao sistema, o ensaio quis libertar-se de algo análogo - Não há texto que, de algum modo, não comece por algum ponto, não prossiga pelo caminho assim aberto e o encerre em alguma parte. Que esses três momentos efetivamente coincidam com "o começo", "o meio" e "o fim" é antes algo buscado pela forma sistemática. Ela quer começar pelo começo - o que significa começar pelo principio, pela proposição fundamental que tudo funda, ou partir ao seu encontro. Assim Descartes narrou no Discurso do método a história de suas "primeiras meditações", cujo inteiro teor não tardaria muito a revelar nas Meditationes de prima philosophia, compartilhando com o leitor sua busca da verdade pelo caminho da dúvida, em contraste com o que faria pouco depois nos Principia, quando já parte da inabalável certeza descortinada pelo cogito. Assim também procedeu Fichte, seja estabelecendo as condições que um primeiro principio teria de satisfazer para que pudesse ser tomado como absolutamente certo, como no escrito programático Sobre o conceito da doutrina da ciência, seja pela encenação de sua busca já na abertura da Fundação de toda a doutrina da ciência. Em obras como essas, nas quais são erguidas as mais altas pretensões sistemáticas, é essencial que a forma interna, com suas partes, divisões e subdivisões, resulte em um todo articulado sob o preceito lógico-metodológico de que deve haver uma "introdução", com a posição do problema, um "desenvolvimento", frequentemente articulado com recapitulações e o tratamento de questões secundárias, e uma "conclusão" que opere o seu remate arquitetônico - portanto, que o todo, por mais labirintico que ele possa ser, perfaça como que um grande raciocínio e seja o mais claro possivel. Na filosofia como na música, a clareza é a condição do que Schönberg e Webern exigiam inflexivelmente: a apreensibilidade (Fasslichkeit) dos pensamentos. É preciso, então, que o autor se empenhe pelo êxito de sua comunicação. Adorno, cuja fala era bem mais cristalina que a sua escrita, quis de algum modo proteger seus textos de toda sorte de instrumentalização, preservando, assim, a integridade dos seus pensamentos e dos seus objetos. É discutivel que sempre tenha tido sucesso; mas ele teve suas razões, também elas discutiveis, para permitir-se uma certa obscuridade.

O ensaio recusa a promessa de rigor e solidez propalada pelo método e se entrega à aventura de pensar sem maiores garantias. Assim ele se aproxima da retórica, "que a mentalidade científica, desde Descartes e Bacon, quis expulsar", embora com êxito duvidoso, como observa Adorno com algum deboche, pois a retórica

acabou por rebaixar-se, na era científica, à
categoria de uma ciência sui generis, a das
comunicações. É verdade que a retórica sem-
pre foi o pensamento adaptado à linguagem
comunicativa. Tal pensamento se voltava para o
imediato: a satisfação substitutiva dos ouvintes.
Exatamente na autonomia da exposição, pela
qual ele se distingue da comunicação cienti-
fica, é que o ensaio preserva agora rastos do
comunicativo de que esta última carece. As
satisfações que a retórica quer proporcionar ao
ouvinte são sublimadas no ensaio na ideia da
felicidade de uma liberdade frente ao objeto,
liberdade que dá mais de si mesma ao objeto
do que se ele fosse inserido inelutavelmente
na ordem das ideias (ADORNO, 1986a, p. 184).

O risco dessa sublimação, a meu ver, é o recalque mesmo do momento comunicativo - um risco que Adorno parece não ter temido correr ao levar aquele impulso às suas últimas consequências, apontando as afinidades entre o ensaio e a música. 
De modo análogo à mudança de função de muitos traços na música autônoma, o persuasivo da comunicação é, no ensaio, tornado estranho à sua meta original, convertendo-se em pura determinação da exposição em si, no caráter coercitivo de sua construção, que não gostaria de copiar a coisa e sim reconstruí-la a partir dos seus membra disiecta conceituais. Mas as indecentes transições da retórica, em que associações livres, plurivocidade das palavras, abandono da síntese lógica facilitavam o trabalho do ouvinte, para submetê-lo, uma vez enfraquecido, à vontade do orador, fundem-se no ensaio com o conteúdo de verdade. Suas transições rechaçam a derivação direta em favor de conexões transversais entre os elementos, para as quais a lógica discursiva não tem espaço (ADORNO, 1986a, p. 185).4

Quanto mais o ensaio se aproxima da música, mais se afasta do resto não absorvido da retórica e da ciência; pois a pretensão à autonomia erguida pela música assim como pelo ensaio resiste ao pura e simplesmente comunicativo na medida em que a forma - ao contrário do que se passa com a música utilitária e com o paper acadêmico, que Adorno não conheceu com esse nome - não é um meio, um veículo, para o qual a linguagem também seria um instrumento. A pretensão de autonomia do ensaio é a pretensão de dignidade de sua forma, cujo corolário é a liberdade do próprio ensaísta. Por isso, a questão não é se "o" ensaio "é" ou não uma forma autônoma, e sim se algum ensaísta conseguiu praticá-lo como tal. Adorno o conseguiu, talvez muito mais pelo seu imenso talento - a única moeda real na economia do espírito - do que pelo valor de suas convicções declaradas.

Enquanto "se libera da ideia tradicional de verdade" (que ora parece ser a do realismo metafísico, ora a de "clareza e distinção"), o ensaio "suspende ao mesmo tempo o conceito tradicional de método" (ADORNO, 1986a, p. 175), cujo grande representante, Descartes, já havia sido apontado por Horkheimer e Marcuse como o patrono da "teoria tradicional" (HORKHEIMER; MARCUSE, 1937. p. 625). O abandono das concepções tradicionais de verdade e método afetam de tal modo a relação do ensaio com os conceitos e com a linguagem, que tudo se decide pelo trabalho mesmo na escrita e na forma da exposição.
O como da exposição deve salvar em termos de precisão o que é sacrificado pela renúncia à abrangência, sem, no entanto, entregar a coisa mentada ao arbitrio de significados conceituais que alguma vez tenham sido decretados. Nisso, Benjamin era o mestre insuperável (ADORNO, 1986a, p. 176).

O pensamento avança pela dinâmica dos conceitos, os quais "devem ser expostos de tal modo que uns carreguem aos outros, que cada um se articule segundo as suas configurações com outros" (ADORNO, 1986a, p. 177). Assim configurados, eles são antes coordenados entre si que subordinados uns aos outros, afigurandose como um "campo de forças" (ADORNO, 1986a, p. 177). Em face da teoria tradicional, o ensaio é "mais aberto", porque recusa o ordenamento sistemático, e também

\begin{abstract}
mais fechado, porque trabalha enfaticamente na forma da exposição. A consciência da não-identidade entre o modo de expor e o objeto impõe um ilimitado esforço à exposição. Isso, e só isso, é que no ensaio é semelhante à arte; fora isso, o ensaio está necessariamente aparentado com a teoria, por causa dos conceitos que nele aparecem e que trazem de fora não só seus significados, mas também o seu referencial teórico (ADORNO, 1986a, p. 181).
\end{abstract}

Essa semelhança com a arte, da qual "o ensaio se diferencia tanto pelos meios que emprega, os conceitos, quanto por sua pretensão à verdade despida da aparência estética" (ADORNO, 1986a, p. 169), revela-se antes de tudo como uma semelhança com a música. É em suas formas orgânicas que ele encontra uma espécie de modelo para a configuração dos conceitos. Assim, o ensaio "roça a lógica musical, a arte rigorosa e, no entanto, sem conceitos, da transição musical, para dar à linguagem falada algo que ela perdeu sob o domínio da lógica discursiva" (ADORNO, 1986a, p. 185) - a saber: o não-idêntico, já evidenciado pela equivocidade das palavras e ao qual o ensaio gostaria de dar voz. Uma vez posto o problema, sua aporia também se apresenta pois, a resistência da "lógica discursiva" se faz sentir no trato mesmo com a linguagem e não oferece nenhuma alternativa: "só é possivel

4 Tradução modificada em confronto com o original. 
superá-la com astúcia, mediante as suas próprias formas e graças à penetrante expressão subjetiva" (ADORNO, 1986a, p. 185).

O motivo da superação do pensamento discursivo através das suas próprias formas reapareceria no coração da Dialética negativa: "A utopia do conhecimento seria abrir com conceitos o desprovido de conceito, sem equipará-los" (ADORNO, 1997c, p. 21, tradução nossa). ${ }^{5}$ Essa já era a utopia do ensaio: "forçar, com conceitos, a abertura do que não tem entrada nos conceitos [...]" (ADORNO, 1986a, p. 186, tradução nossa). ${ }^{6}$ Já o motivo da expressão subjetiva remete antes ao que, para o ensaísta, teria a força de um direito natural: o de falar de si e sobre o que the ocorre, o "momento expressivo da filosofia", tal como Adorno aprendera com Kracauer (ADORNO, 1997d, p. 389). É significativo que ambos os motivos sejam colocados aqui sob o conceito de "lógica musical". Ele remonta ao ambiente da musica poetica e a Johann Nicolaus Forkel, que o introduziu em 1788; mas ninguém atribuiu tanta importância à "lógica musical" quanto Schönberg (DAHLHAUS, 1986, p. 290). Adorno, aparentemente, a equipara à "arte rigorosa e, no entanto, sem conceitos, da transição musical". Ainda que no desenvolvimento dos seus motivos e em suas sucessivas transições o ensaio apenas roce a lógica musical, isso não é um simples detalhe e sim algo que implica diretamente o como da exposição, pois aqui estão em jogo as "conexões transversais entre os elementos, para as quais a lógica discursiva não tem espaço" (ADORNO, 1986a, p. 185). Isso remete, por um lado, à relação com a equivocidade das palavras, pois o ensaio quer "recuperar aquilo que a crítica do equivoco, a mera distinção de significados raramente alcançou: que, onde quer que uma palavra cubra coisas diversas, a diversidade não seria inteiramente diversa; que a unidade da palavra advertiria sobre uma unidade na coisa, ainda que recôndita [...]" (ADORNO, 1986a, p. 185). Um exemplo disso seria a palavra Versuch, frequentemente usada como sinônimo de "ensaio": essa palavra, em que a utopia do pensamento - acertar no miolo da questão - se conjuga com a consciência da própria falibilidade e transitoriedade, transmite uma informação sobre a forma, tanto mais digna de nota quanto não é programática, mas é caracteristica da intenção tateante (ADORNO, 1986a, p. 185).

Sob esse aspecto, Adorno se aproxima de Montaigne, pois a palavra essai designa antes uma forma mentis, uma atitude espiritual, e não um "gênero literário". O grande antagonista do ensaio é o sistema, que não é "gênero literário" algum; e embora as críticas de Adorno à forma sistemática atinjam objetivamente a arquitetônica dos tratados, eles não são mencionados, a não ser uma única vez, e mesmo assim indiretamente, através de uma citação do ensaio de Max Bense sobre o ensaio (ADORNO, 1986a, p. 180).

Por outro lado, a analogia com a lógica musical toca à relação do ensaio com os seus objetos - e assim chegamos ao motivo do "primado (Vorrang) do objeto" ou, sendo mais preciso, a um aspecto interessante e talvez não notado desse motivo. Martin Jay referiu-se à filosofia de Adorno como uma "filosofia atonal".7 O que soa como um achado mais ou menos sagaz sugere antes uma analogia pouco óbvia entre o ensaio como a forma por excelência da filosofia de Adorno e certos problemas artesanais da música atonal, particularmente de Schönberg. A emancipação da dissonância resultou em novas dificuldades para a lógica da composição, pois o desenvolvimento dos pensamentos musicais por variações progressivas já não mais tinha à sua base as coordenadas harmônicas. Em principio, pode-se transitar subitamente em qualquer direção. $O$ atonalismo privou as formas musicais de uma certa estrutura, deixando-as virtualmente um tanto invertebradas. Daí a predileção de Schönberg pelas formas breves; daí também o recurso a um texto, especialmente nas grandes formas. Schönberg lançou mão desse recurso e fez do texto um esteio seguro, uma espécie de substituto da tonalidade, capaz de legitimar a aparente arbitrariedade do nexo de sentido

\footnotetext{
Do original: Die Utopie der Erkenntnis wäre, das Begriffslose mit Begriffen aufzutun, ohne es ihnen gleichzumachen. Cf. tb. p. 27.

É esse o título do segundo capítulo de seu livro Adorno (1984)
} 
musical, dando-lhe mais unidade (SCHÖNBERG, 2007, p. 131; DAHLHAUS, 1986, p. 290-291).

O ensaio tira todas as consequências da crítica ao sistema assim como a música atonal em face do tonalismo; mas o que para a música atonal fora um hábil expediente artesanal é para o ensaio uma questão de vida ou morte. Ao voltar-se contra a forma sistemática, mas sem renunciar totalmente à forma orgânica, o ensaio experimenta um desamparo semelhante ao do compositor no manejo das grandes formas. Como esse, o ensaísta também encontra o seu apoio em algo já formado.

Astutamente, o ensaio se aferra aos textos como se eles simplesmente estivessem aí e tivessem autoridade. Assim, sem o engodo do primordial, passa a ter um chão debaixo dos pés, por duvidoso que este seja, comparável à antiga exegese teológica dos textos. A tendência é, no entanto, oposta, é crítica: pelo confronto dos textos com o seu próprio e enfático conceito, com a verdade visada por cada um, mesmo que ele não a tenha em mente, abalar a pretensão da cultura, levando-a a meditar sobre sua inverdade, que é exatamente essa aparência ideológica, em que a cultura se revela como natureza decaída. Sob o olhar do ensaio, a segunda natureza toma consciência de si como primeira. (ADORNO, 1986a, p. 183-184). ${ }^{8}$

As reflexões de Adorno sobre o ensaio lançam muitas luzes sobre a sua fisionomia intelectual e sua genealogia como músico e filósofo, mas são tanto menos convincentes quanto mais simplificam os seus alvos. Penso em motivos que há muito perderam sua força, como é o caso das concepções "tradicionais" de verdade e método, particularmente quando vinculadas ao apelo de uma prima philosophia fundada sobre uma certeza indubitável. Além disso, penso, principalmente, em uma certa dramaticidade que dá o tom dos ataques de Adorno ao impeto "classificatório" da "lógica discursiva", em especial quando mobiliza motivos metafísicos e teológicos. Também nisso, Benjamin fora um mestre.
Pois o elemento diferenciador de sua filosofia é o seu modo de concreção. Como o seu pensar trata de subtrair-se ao classificatório com empenhos sempre renovados, assim também, para ele, o nome das coisas e dos homens é o protótipo de toda esperança e sua reflexão procura reconstruir o nome. [...] Para ele, a filosofia consistia essencialmente em comentário e critica, e ele reconhecia à linguagem mais dignidade como cristalização do 'nome' do que como portadora do significado e da expressão (ADORNO, 1986c, p. 190, 193).

Muitas obscuridades, frequentemente mescladas aos juizos mais certeiros, foram ditas de bonne foi sob a chancela desse motivo. A linguagem da música, por exemplo, seria essencialmente distinta da linguagem ordinária, mas não por motivos evidentes, e sim pelo que, para Adorno, seria o seu

aspecto teológico. O que ela diz, enquanto o que nela aparece, está ao mesmo tempo determinado e encoberto. Sua ideia é a figura do nome divino. Ela é prece desmitologizada, livre da magia da provocação de influências; a tentativa humana, como sempre também em vão, de dizer o próprio nome e não de comunicar significados (ADORNO, 1997e, p. 252).

Afinada nesse registro, a prosa alegórica de Kafka seria muito mais musical que os melodiosos versos de Swinburne ou Rilke, pois nela o sentido está sempre determinado e encoberto (ADORNO, 1997e, p. 252). Embora a observação seja fina e justa, o direito a essa musicalidade, tão legítimo em Kafka, é o direito ao enigmático, do qual o ensaio pode e deve prescindir inteiramente, sob pena de tornar ainda mais frágil a sua precária autonomia (BARBOSA, 2020); mas não se pode dizer que Adorno estivesse convencido disso, como atesta sua impressionante, e mesmo admirável, apologia da prosa de Hegel, quando ataca as ideias tradicionais de clarté et distinction (ADORNO, 1997f, p. 331).

Enquanto resiste ao pensamento discursivo, cujo ímpeto classificatório recalcaria o nãoidêntico, o ensaio também resistiria à sua linearidade, pela qual esse impeto consumar-

8 O ensaio é "a forma crítica par excellence; e isso como crítica imanente das formações espirituais, como confrontação daquilo que elas são com o seu conceito: crítica da ideologia" (ADORNO, 1986a, p. 182). Benjamin seria lembrado como um mestre desse olhar: O ensaio como forma consiste na capacidade de contemplar o histórico, as manifestações do espírito objetivo, a 'cultura', como se fossem natureza. Benjamin tinha essa capacidade como poucos" (ADORNO, 1986c, p. 192). 
se-ia. A utopia do conhecimento - ultrapassar o conceito pelo próprio conceito - implicaria então forçar essa linearidade desde dentro, abrindo espaço às conexões transversais e às simultaneidades, como se o pensamento discursivo só pudesse ser salvo do seu destino "homofônico" por precisos efeitos "polifônicos". É significativo que Adorno, ao contrário de Marcuse, admirasse a técnica weberiana da definição dos conceitos históricos; pois Weber não procedia per genus proximum et differentiam specificam, e sim pela progressiva composição das notas características dos conceitos no curso mesmo da apresentação do trabalho empírico - algo a que aplicou-se com extremo cuidado, apesar de sua prosa pesada e tortuosa (ADORNO, 1997c, p. 166; 167). Fascinado pela música, tudo o que ele queria era poder escrever como um compositor. Quando viu pela primeira vez a partitura da redução para piano de Tristão e Isolda, teria dito: "tal técnica de escrita teria de estar à minha disposição, pois assim finalmente poderia, como o deveria, dizer muitas coisas separadamente e, no entanto, ao mesmo tempo" (BAUMGARTEN, 1964, p. 482-483).

Mas enquanto se deixa persuadir por Nietzsche, vendo nos conceitos apenas uma rude dureza niveladora, apenas o impeto de reduzir o não idêntico ao idêntico (WELLMER, 1985, p. 147-149), Adorno não faz justiça ao pensamento discursivo. Retoricamente, vocifera contra a tragédia da predicação, contra o sacrificio do singular no altar do universal, acenando com a configuração do "nome", como se as notas características de um conceito não se combinassem como acordes e se deixassem ouvir nas metáforas, sobre as quais, aliás, nada diz, e mesmo nas predicações literais; como se as linhas de um texto não fossem como uma melodia à espera de que o leitor executasse o baixo contínuo; como se a linearidade do pensamento discursivo, forçado a parar e a recomeçar todo o tempo, não fosse interrompida pelo próprio pensamento. 0 trabalho da forma se aninha nesse movimento, no qual a linguagem, por amor ao verdadeiro, se deixa modelar sem violência. Por isso, é ingênuo supor que enquanto "roça a lógica musical, a arte rigorosa e, no entanto, sem conceitos da transição musical", o ensaio possa "dar à linguagem falada algo que ela perdeu sob o domínio da lógica discursiva", pois, a rigor, não há nada "perdido". Também, por isso, embora insista com razão que o ensaio "não é alógico", que "obedece a critérios lógicos na medida em que o conjunto de suas frases tem de compor-se coerentemente" (ADORNO, 1986a, p. 185), é discutivel a suposição de que a forma mesma não esteja de algum modo sob esse regime lógico. Mas, de acordo com Adorno, enquanto recusa o principio da forma sistemática - o da derivação do todo a partir de uma proposição primeira - o ensaio "coordena os elementos, ao invés de subordinálos; e só a essência de seu conteúdo, não o seu modo de exposição, é que é comensurável aos critérios lógicos" (ADORNO, 1986a, p. 185-186). Também nisso Benjamin foi o seu mestre. "Com uma risadela calada, aprendeu a demonstrar o caráter oco das arcaicas pretensões da prima philosophia. Todas as suas manifestações estão à mesma distância do ponto central" (ADORNO, 1986c, p. 191). Lê-se o mesmo em um aforismo de Minima moralia: "Em um texto filosófico, todas as proposições deveriam situar-se a igual distância do centro" (ADORNO, 1992, p. 61). Metáforas como a da constelação e do mosaico restituem esse ideal formal - embora haja aqui uma certa incongruência pois, a imagem de um "ponto central" é tão estranha quanto suspeita para o ensaio, excêntrico desde sempre (PEREIRA, 2018, p. 47). Tal imagem (Benjamin pensava em Paris, na Étoile...) remete propriamente à ideia do sistema nucleado por um princípio supremo, como em Fichte. ${ }^{9}$ Como se não fosse esse o caso, o ensaio

\footnotetext{
9 "Mas, se porventura não deve haver meramente um ou vários fragmentos de sistema [...] ou vários sistemas [...]. mas um sistema perfeito e único no espirito humano, tem de haver tal principio supremo e absolutamente primeiro. Por mais que, a partir dele, nosso saber se estenda em muitas séries, e de cada uma dessas partam novas séries, e assim por diante, todas elas têm contudo de estar firmadas em um único elo, que não está fixado em nada, mas sustenta por sua própria força a si mesmo e ao sistema inteiro. - Temos agora um globo terrestre que se sustenta por sua própria força de gravidade, cujo centro atrai poderosamente tudo aquilo que tivermos construido, desde que efetivamente em seu âmbito, e não eventualmente no ar, e desde que perpendicularmente, e não - digamos - obliquamente, e nem um grãozinho de poeira pode ser subtraido de sua esfera" (FICHTE, 1980, p. 19, SW 1, 54).
} 
adorniano faz valer o seu impulso antissistemático, permitindo-se saltos, interrupções e transições abruptas, repugnantes ao senso lógico. Essa descontinuidade, incomensurável aos critérios lógicos, seria também, para Adorno, legitimada pela Stimmigkeit do próprio objeto: "A continuidade da exposição estaria em contradição com a natureza antagônica do objeto enquanto não definisse a continuidade simultaneamente como descontinuidade" (ADORNO, 1986a, p. 179-180). Como um esteio comparável ao texto nas grandes formas atonais, o objeto também legitima a aversão do ensaio à completude. Sob esse aspecto, quanto mais o ensaio se afasta do sistema, mais se aproxima do fragmento.

Enquanto se rebela esteticamente contra o estrito método de não deixar nada fora, o ensaio obedece a um motivo de ordem epistemológica. A concepção romântica do fragmento - como uma formação nem completa nem exaustiva do tema, mas que através da auto-reflexão vai avançando até o infinito - defende esse tema anti-idealista no próprio seio do idealismo (ADORNO, 1986a, p. 180).

Na medida em que o progresso ad infinitum da reflexão consiste na dinâmica mesma da ironia romântica - pois somente com ironia pode o homem, ser finito, aproximar-se do incondicionado -, o que para Adorno se afigura como uma defesa de um motivo anti-idealista no seio do idealismo é antes uma expressão da deriva estética do próprio idealismo, com o qual o ensaio tem muito mais em comum do que talvez pudesse admitir.

A força do elogio adorniano do ensaio encontra-se antes em sua defesa da filosofia como uma atividade crítica - e não como uma ciência - e na estratégia mesma dessa defesa; pois perguntar filosoficamente pela autonomia do ensaio significa perguntar pelo ensaio como forma - e não como "gênero". Por isso Adorno não o comparou com outros "gêneros poéticos", como se ele fora um "quarto gênero poético", preferindo confrontá-lo com o princípio da forma sistemática, de acordo com o qual a lógica discursiva e as regras de inferência determinam diretamente a forma de exposição. Contudo, o conceito clássico - "tradicional" - da forma sistemática, tal como o encontramos em Descartes e Fichte, implica um tipo de fundacionismo que, a rigor, já não mais convence ninguém; e Adorno mesmo contribuiu fortemente para o enfraquecimento tanto desse fundacionismo como da crença numa "filosofia da origem" (Ursprungsphilosophie). Contra uma "primeira", ele apelou a uma filosofia "última". (ADORNO, 1997g, p. 47; BARBOSA, 2006).

Hume, talvez o primeiro ensaísta que escreveu um ensaio sobre o ensaio, comparou o duradouro frescor de Catulo com o brilho efêmero dos epigramas de Marcial, cujas tiradas não resistiriam a uma segunda leitura (HUME, 2011, p. 160-161). É o que se passa quando comparamos o melhor de Adorno - suas brilhantes análises musicais - com seus muitos ditos e desditos sobre o método, a verdade, a prima philosophia, o sistema, a ciência, a lógica, o idêntico e o não-idêntico. Eles soam tão previsiveis quanto uma cadência perfeita. A defesa adorniana do ensaio completou sessenta anos, mas, diferentemente da do jovem Lukács, não precisou de tanto tempo para tornarse uma peça "clássica": ela tem um justo lugar de honra nas melhores antologias de ensaios sobre o ensaio. Seja com o seu auxílio ou mesmo apesar dele, o ensaio, tout compte fait, saiu-se até vitorioso, embora sua presença obrigatória nos programas do Abitur e do baccalauréat, escoltada pela profusão de livros e materiais didáticos que ensinam adolescentes a escrever "ensaios", talvez não fale muito a seu favor. Ao contrário do que julgou Adorno, a atualidade do ensaio não é mais a do anacrônico (ADORNO, 1986a, p. 186), a não ser que a filosofia como uma atividade crítica seja um eterno anacronismo; mas, ao que parece agora, sua defesa da forma ensaio tornou-se em parte tão velha quanto quase tudo o que ela condenou.

\section{Referências}

ADORNO, T. W. O ensaio como forma. In: COHN, G. (org.). Theodor W. Adorno. Tradução Flávio R. Kothe. São Paulo: Ática, 1986a. (Coleção Grandes Cientistas Sociais, v. 54).

ADORNO, T. W. Die Aktualität der Philosophie. In: Philosophische Frühschriften. Gesammelte Schriften. Bd. 1. Frankfurt am Main: Suhrkamp, 1997a.

ADORNO, T. W. Titel. In: Noten Zur Literatur. Gesammelte Schriften. Bd. 11. Frankfurt am Main: Suhrkamp, 1997b. 
ADORNO, T. W. Por que é dificil a música nova. In: COHN, G. (org.). Theodor W. Adorno. Tradução Flávio R. Kothe. São Paulo: Ática, 1986b. (Coleção Grandes Cientistas Sociais, v. 54).

ADORNO, T. W.. Negative Dialektik. In: Gesammelte Schriften. Bd. 6. Frankfurt am Main: Suhrkamp, 1997c.

ADORNO, T. W. Der wunderliche Realist. In: Noten Zur Literatur. Gesammelte Schriften. Bd. 11. Frankfurt am Main: Suhrkamp, 1997d.

ADORNO, T. W. Caracteristica de Walter Benjamin. In: COHN, G. (org.). Theodor W. Adorno. Tradução Flávio R. Kothe. São Paulo: Ática, 1986c. (Coleção Grandes Cientistas Sociais, v. 54).

ADORNO, T. W. Fragment über Musik und Sprache. In: Quasi Una Fantasia. Gesammelte Schriften. Bd. 16. Frankfurt am Main: Suhrkamp, 1997e.

ADORNO, T. W. Skoteinos oder Wie zu lesen sei. In: Drei Studien Zu Hegel. Gesammelte Schriften. Bd. 5. Frankfurt am Main: Suhrkamp, 1997f.

ADORNO, T. W. Minima moralia. Tradução Luiz Eduardo Bicca. São Paulo: Ática, 1992.

ADORNO, T. W. Zur Metakritik der Erkenntnistheorie. In: Gesammelte Schriften. Bd. 5. Frankfurt am Main: Suhrkamp, 1997g.

BARBOSA, R. O ensaio como forma de uma "filosofia última": Sobre T. W. Adorno. In: PESSOA, F. (org.). Arte no pensamento. Vila Velha: Museu Vale do Rio Doce, 2006.

BARBOSA, R. Zur Dialektik von Musik und Sprache Die Sprachähnlichkeit der Musik nach Adorno. Musik \& Ästhetik, Jg. 24, Heft 01, p. 42-57, 2020.

BAUMGARTEN, E. (org.). Max Weber: Werk und Person. Tübingen: J. C. B. Mohr (Paul Siebeck), 1964.

DAHLHAUS, C. Das Verhältnis zum Text. Zur Entwicklung von Arnold Schönbergs musikalischer Poetik. In: ALLROGEN, G.; ALTENBURG, D. (org.). Festschrift Arno Forchert zum 60. Geburtstag am 29. Dezember 1985. Kassel, Basel, London, Nova York: Bärenreiter, 1986.

FICHTE, J. G. Sobre o conceito da doutrina da ciência. In: Fichte. Tradução Rubens Rodrigues Torres Filho. São Paulo: Abril, 1980. (Coleção Os Pensadores).

HORKHEIMER, M.; MARCUSE, H. Philosophie und kritische Theorie. Zeitschrift für Sozialforschung, [s. l.], v. 6, 1937. DOI: https://doi.org/10.5840/zfs1937635

HUME, D. Da simplicidade e do refinamento na arte de escrever. In: PIMENTA, Pedro Pimenta; SUZUKI, Márcio. A arte de escrever ensaio e outros ensaios (morais, políticos e literários). Tradução Márcio Suzuki e Pedro Pimenta. São Paulo: Iluminuras, 2011.

JAY, M. Adorno. Cambridge: Harvard University Press, 1984.

KAYSER, R. Wege des Essays. Die neue Rundschau, [s. l.], ano 36, v. 2, 1925.

KERR, A. Einleitung zu den Gesammelten Schriften. In: Theaterkritiken. Stuttgart: Reclam, 1972.
LUKÁCS, G. Über Wesen und Form des Essays: Ein Brief an Leo Popper. In: Die Seele und die Formen. Neuwied: Luchterhand, 1971.

PEREIRA, L. M. Sobre os ensaistas ingleses. In: PIRES, P. R. (org.). Doze ensaios sobre o ensaio: antologia serrote. São Paulo: IMS, 2018.

SCHÖNBERG, A. Fundamentos da composição musical. Tradução Eduardo Seincman. São Paulo: Editora da Universidade de São Paulo, 2012.

SCHÖNBERG, A. Gesinnung oder Erkenntnis? In: MORAZZONI, Anna Maria (org.). Stile herrschen, Gedanken siegen. Ausgewählte Schriften. Mainz: Schott, 2007.

WELLMER, A. Adorno, Anwalt des Nicht-Identischen. Eine Einführung. In: Zur Dialektik von Moderne und Postmoderne. Vernunftkurtik nach Adorno. Frankfurt am Main: Suhrkamp, 1985.

\section{Ricardo Barbosa}

Doutor em Filosofia pela PUCRJ (Rio de Janeiro, RJ, Brasil). Professor na Universidade do Estado do Rio de Janeiro (Uerj), Rio de Janeiro, RJ, Brasil.

\section{Endereço para correspondência}

Ricardo Barbosa

Universidade do Estado do Rio de Janeiro

Programa de Pós-Graduação em Filosofia

Rua São Francisco Xavier, 524, sala 9037, bloco F

Maracanã, 20550-900

Rio de Janeiro, RJ, Brasil 